\title{
Advanced Nano-based Manipulations of Molasses in the Cellulose and Paper Discipline: \\ Introducing A Master Cheap Environmentally Safe Retention Aid \& Strength Promoter in Papermaking
}

\section{By}

Tamer Y. A. Fahmy ${ }^{*}$ and Fardous Mobarak

Cellulose and Paper Department, National Research Center, Sh. El-Tahrir, Dokki, Cairo, Egypt.

*Correspondence to: Dr. Tamer Y. A. Fahmy, Cellulose and Paper

Department, National Research Center, Sh. El-Tahrir, Dokki,

Cairo, Egypt.

E-mail: drtamer_y_a@yahoo.com

The original article is available at Carbohydrate Polymers website 


\section{ABSTRACT}

This work introduces, for the first time worldwide, molasses -a byproduct of the sugar industry- as a master retention aid and strength promoter in papermaking. The paper nanocomposites produced in the present work -involving molasses, natural cellulose fibers, and kaolin- retained larger amounts of kaolin while exhibiting greater strength, as compared to their molasses-free counterparts. Recently, the authors have shown, for the first time, that the nanoadditive sucrose can overcome the ultimate fate of deterioration in strength of paper, due to addition of inorganic fillers such as kaolin. This deterioration was counteracted by incorporating the nanoporous structure of cellulose fibers with sucrose, which leads to incorporation beating of the fibers, and thus increases the strength of the produced paper nanocomposites. In addition, the nanoadditive sucrose was proven -for the first time- to act as retention aid for inorganic fillers such as kaolin. We called this phenomenon incorporation retention to differentiate it from the conventional types of retention of inorganic fillers. On the other hand, it is well established in the literature that using gums (including starch) as additives in papermaking enhances the strength of paper. Molasses contains both the nanoadditive (sucrose), and gums (including starch). Molasses is a byproduct of sugar industry, which is cheaper than sucrose; and a major part of sucrose lost in sugar industry resides in molasses. Moreover, molasses is an environmentally safe 
additive. Therefore, the nanoadditive (molasses) was chosen, in the present work, to be manipulated as a master strength promoting retention aid for inorganic fillers used in papermaking, such as kaolin. 


\section{Introduction and Object :-}

The authors and others, in recent work, successfully manipulated the natural nanoporous structure of cellulose fibers to increase the water absorption and reactivity of cellulose fibers, to produce water absorbent paper nanocomposites, or to greatly increase the strength of paper made from cellulose fibers. This was achieved by incorporating the nanoporous structure, of water swollen cellulose fibers, by the nanoadditives sucrose and glucose $[1,2]$.

It was shown that sucrose and glucose molecules are entrapped in the cell wall nanopores of cellulose fibers, during the collapse of these pores, as the fibers are dried. The sucrose and glucose molecules act as spacers, and prevent the irreversible collapse of the natural nanoporous structure of cellulose fibers, which -normally- occurs during drying. Thus the incorporation of sucrose or glucose into cellulose fibers leads to nanocomposites of increased water uptake (water retention value), and increased reactivity (i.e. increased accessibility to reagents) [1,2].

It was, also, shown that incorporating the nanoporous structure of cellulose fibers, with sucrose, leads to paper nanocomposites of enhanced strength (breaking length). The cell walls, on both sides of the incorporated sucrose spacers, are stressed during drying because sucrose spacers hinder them to relax. This leads to a strain, which makes some microfibrils partially released and protrude out of the fibers. This in turn p 4 of 20 tp 
leads to more efficient entanglement of the fibers, and hence increases the strength of the prepared paper nanocomposites. In other words, a sort of fibers beating takes place. The authors and others called this phenomenon incorporation beating to differentiate it from chemical and mechanical beatings, conventionally applied to increase the strength of paper [1].

These successful results encouraged the authors to expand the studies -for the first time- to a sugar industry byproduct rich in sucrose, which is molasses. Using this byproduct, as an additive for cellulose fibers, succeeded in producing paper nanocomposites of enhanced dry and wet strength and improved water absorbance [3, 4].

It is worth mentioning that when aqueous solutions of sucrose are equilibrated with the water-swollen pulp (cellulose fibers), sucrose should be able to penetrate into every micropore or nanopore larger than $8 \AA$ (0.8 nanometer). The volume of these sucrose-accessible pores amounts to $86.5 \%$ of the total pore volume of the micropores. Thus, the dissolved sucrose molecules should be distributed rather uniformly throughout the fiber cell wall, except for pores less than $8 \AA$ in size. These calculations are based on the solute exclusion data of Stone and Scallan and the size of the sucrose molecules derived from them [5].

Recently [6], the authors succeeded -for the first time- to manipulate the strength promoting effect of sucrose as a means to counteract the ultimate fate of deterioration in strength of paper, due to p 5 of 20 tp 
addition of inorganic fillers such as kaolin. In addition, sucrose was proven -for the first time- to act as retention aid for inorganic fillers such as kaolin. The authors called this phenomenon incorporation retention to differentiate it from the conventional types of retention of inorganic fillers [6].

To achieve these aims, the authors prepared an advanced paper nanocomposite involving two additives $-\mathrm{a}$ nanoadditive and a conventional additive- within a matrix of natural cellulose fibers. The first additive (the nanoadditive) is sucrose, which incorporates the nanoporous structure of the cell walls of cellulose fibers. The second additive (the conventional additive) is kaolin, the famous paper filler. Kaolin is enmeshed between the adjacent cellulose fibers. This advanced paper nanocomposite was prepared by simple techniques [6].

On the other hand, it is well established in the literature that using gums (including starch) as additives in papermaking enhances the strength of paper [7].

Molasses contains both the nanoadditive (sucrose), and gums (including starch). Molasses is a byproduct of sugar industry, which is cheaper than sucrose; and a major part of sucrose lost in sugar industry resides in molasses. Therefore, molasses was chosen, in the present work, to be manipulated as a cheap master retention aid and strength promoter in papermaking.

p 6 of 20 tp 
Molasses is an important byproduct of the sugar-extraction process. The liquid discharged by the centrifugals in the last stage of sugarcane juice processing, after no more sugar can be separated from the sugarcane juice by usual factory methods, is called final molasses. Molasses contains sucrose, which cannot be recovered by economic methods. Sucrose (lost in molasses) represents the highest proportion of the losses incurred in the processing of sugarcane. This loss may reach about $9 \%$ of the total sucrose. Thus sucrose lost in molasses is a major consideration, and is the principal reason for the varied and extensive inquiries which have been conducted on the profitable utilization of this valuable byproduct. The sucrose content in molasses may range from about $32 \%$ $44 \%$. In addition to sucrose, reducing sugars are present in molasses, namely glucose and fructose. The content of reducing sugars ranges from about 10 to 15 percent. Thus the principal value of molasses as an industrial raw material lies in its content of fermentable sugars, which amounts to about $50 \%$ by weight. Gums (including starch) are also present in molasses. The content of gums (including starch) ranges from about 3 to 5 percent by weight [8]. 


\section{Materials and Methods: -}

- The cellulose fibers (pulp fibers) used in this work were high alpha cellulose wood pulp fibers. We have carried out chemical and physical analyses for this pulp. The results of the analyses and physical properties are reported in Table 1.

- The conventional additive (inorganic filler kaolin) used in this work was Egyptian upgraded kaolin prepared on pilot scale, kindly provided by Metallurgical Research and Development Institute, El-Tebeen, Egypt. Its specifications and analyses are: Kaolinite $92.43, \mathrm{Al}_{2} \mathrm{O}_{3} 35.21 \%$, total $\mathrm{SiO}_{2}$ $44.43 \%, \mathrm{Fe}_{2} \mathrm{O}_{3} 0.92 \%, \mathrm{TiO}_{2} 1.38 \%$, moisture content $0.73 \%$, ash content $87.99 \%$, and brightness $73.90 \%$. The bulk density of this kaolin was 0.846 before grinding and 1.1813 after grinding.

- Filling the cellulose fibers (pulp fibers) with the conventional additive (inorganic filler kaolin): -

In all experiments, the cellulosic fibers were mixed with kaolin and beaten for 15 minutes. The consistency was adjusted to $6 \%$. The fibers were filled with increasing kaolin quantities $(5,10,15$ and $20 \mathrm{~g}$ of kaolin per 100g of pulp fibers).

- Incorporating the nanoadditive (molasses) into the nanoporous structure of cell walls of kaolin-filled cellulose fibers (pulp fibers): -

The incorporation methods used in the present work were recently established by the authors and others $[1-4,6]$. After several preliminary p 8 of 20 tp 
experiments, we fixed the optimum conditions for manipulating the nanoadditive (molasses) as a retention aid and strength promoter. The beaten nondried kaolin-filled fibers were incorporated with molasses solution of the concentration $10 \% \mathrm{w} / \mathrm{w}$, and stirred in the mixer for 15 minutes.

\section{- Paper Sheet Making: -}

Paper sheet composites were made from fibers filled with kaolin only, and paper sheet nanocomposites were made from molasses-incorporated kaolin-filled fibers. The paper sheets were prepared according to the SCA standard, using the SCA - model sheet former (AB Lorenzen and Wetter).

- Determination of the retention value of the inorganic filler kaolin: -

The amounts of the inorganic filler kaolin, retained in the kaolin-filled paper sheet composites and in the molasses-incorporated kaolin-filled paper sheet nanocomposites, were determined by ignition of accurately weighed paper sheets. The retention value was calculated as the ratio of the amount of filler retained in the paper sheet to that originally added. The loss resulting from filler dehydration due to ignition was taken into consideration [9-11]. The retention value was calculated by the formula: Retention Value $\%=$ (wt of retained kaolin/wt of added amount of kaolin) X 100 


\section{Results and Discussion: -}

\section{Effect of Filling Cellulose Fibers (Pulp Fibers) with the}

\section{Conventional Additive (Inorganic Filler Kaolin), in Absence}

\section{of Molasses: -}

$\underline{\text { Table } 2}$ shows the properties of paper composites made from cellulose fibers, filled with increasing amounts of kaolin $(5,10,15$ and $20 \mathrm{~g}$ of kaolin per $100 \mathrm{~g}$ of fibers).

It is evident from Table $\mathbf{2}$ that the strength (breaking length) of the paper composites decreased with increasing the amount of added kaolin. The breaking length of the blank (kaolin-free paper) was $2100 \mathrm{~m}$, while that of the kaolin-filled paper composites decreased to $1612 \mathrm{~m}$, due to addition of $20 \mathrm{~g}$ of kaolin per $100 \mathrm{~g}$ of fibers. Thus the percentage decrease in breaking length, due to addition of kaolin, reached $23.24 \%$.

Also, the wet breaking length of paper composites decreased due to addition of kaolin. The wet breaking length of the blank (kaolin-free paper) was $410 \mathrm{~m}$, while that of the kaolin-filled paper composites decreased to $293 \mathrm{~m}$, due to addition of $20 \mathrm{~g}$ of kaolin per $100 \mathrm{~g}$ of fibers. Thus the percentage decrease in wet breaking length, due to addition of kaolin, reached about $28.54 \%$.

This decrease in strength (breaking length) of the paper composites is a normal phenomenon, observed due to addition of inorganic fillers 
such as kaolin. These fillers are enmeshed between the adjacent cellulose fibers, and hence interrupt the inter-fiber bonding between adjacent fibers $[7,9-12]$.

\section{$\underline{\text { 2. Effect of Incorporating the Kaolin-Filled Cellulose Fibers }}$}

with the Nanoadditive (Molasses) on the Properties of the

\section{Produced Advanced Paper Nanocomposites : -}

In these experiments, the beaten nondried kaolin-filled cellulose fibers (pulp fibers) were incorporated with molasses solution of the concentration $10 \% \mathrm{w} / \mathrm{w}$. Paper sheet nanocomposites were prepared from these beaten nondried kaolin-filled molasses-incorporated fibers, as mentioned in the experimental part.

Table 3 shows the properties of paper nanocomposites made from the molasses incorporated kaolin-filled cellulose fibers, at increasing amounts of kaolin, of 5, 10, 15 and $20 \mathrm{~g}$ per $100 \mathrm{~g}$ of fibers.

It is evident by comparing Table $\mathbf{3}$ and $\underline{\text { Table } \mathbf{2}}$ that the breaking length of paper nanocomposites, produced from molasses-incorporated kaolin-filled fibers, is greater than that of paper composites produced from the kaolin-filled molasses-free fibers. This is true for all the added amounts of kaolin. At addition of $20 \mathrm{~g}$ of kaolin per $100 \mathrm{~g}$ of fibers, the breaking length of the kaolin-filled molasses-free paper composites was $1612 \mathrm{~m}$, while that of the molasses-incorporated kaolin-filled 
paper nanocomposites was $2509 \mathrm{~m}$. Thus, there is a percentage increase of $55.64 \%$ in the breaking length, due to incorporation of the cellulose fibers by molasses.

It is evident from Table $\mathbf{3}$ that the breaking length of the molassesincorporated kaolin-filled paper nanocomposites, even, surpassed the breaking length of the blank (kaolin-free paper). This was true for all the added amounts of kaolin. Even at the highest amount of added kaolin (20g per $100 \mathrm{~g}$ of fibers), the breaking length of the molasses-incorporated kaolin-filled paper nanocomposites was greater, by about $19.48 \%$, than that of the blank kaolin-free paper.

The wet breaking length of paper nanocomposites, produced from molasses incorporated kaolin-filled fibers, was greater than that of paper composites produced from the kaolin-filled molasses-free fibers (compare Table 2 and $\underline{\text { Table } 3 \text { ). }}$. This is true for all the added amounts of kaolin. At addition of $20 \mathrm{~g}$ of kaolin per $100 \mathrm{~g}$ of fibers, the wet breaking length of the kaolin-filled molasses-free paper composites was $293 \mathrm{~m}$, while that of the molasses-incorporated kaolin-filled paper nanocomposites was $473 \mathrm{~m}$. Thus, incorporation of the cellulose fibers, with molasses, led to a percentage increase of $61.43 \%$ in the wet breaking length.

$\underline{\text { Table } 3}$ shows that the wet breaking length of the molassesincorporated kaolin-filled paper nanocomposites, even, surpassed the wet p 12 of 20 tp 
breaking length of the blank (kaolin-free paper). This was true for all the added amounts of kaolin. Even at the highest amount of added kaolin (20g per $100 \mathrm{~g}$ of fibers), the wet breaking length of the molassesincorporated kaolin-filled paper nanocomposites was greater, by about $15.37 \%$, than that of the blank kaolin-free paper.

It is clear from these results that incorporating cellulose fibers, with molasses, succeeded in counteracting the deterioration in strength of paper, that occurs due to addition of inorganic fillers such as kaolin. Sucrose -present in molasses- acted as a strength promoter in the paper nanocomposites, produced from the molasses-incorporated kaolin-filled fibers. The strength (breaking length) of these paper nanocomposites, even, surpassed that of the blank (filler-free paper). Incorporating cellulose fibers, with sucrose, leads to incorporation beating of the fibers, and thus increases the strength of the produced paper nanocomposites.

Moreover, the gums and starch -present in molasses- exerted an additional strength promoting effect. 


\section{The Role of the Nanoadditive (Molasses) as a}

\section{Retention Aid for Inorganic Fillers Such as Kaolin: -}

Table 4 shows the retention value of kaolin for both the kaolin-filled molasses-free paper composites, and the kaolin-filled molasses incorporated paper nanocomposites.

It is evident from $\underline{\text { Table } 4}$ that incorporation of cellulose fibers, by molasses, resulted in an increase in the amount of kaolin retained in the produced paper nanocomposites, relative to the case of the molasses-free kaolin-filled paper composites. This was true for all the added amounts of kaolin. There was a percentage increase of about $177.54 \%$ in the retention value of kaolin, due to incorporation of the cellulose fibers by molasses (at added amount of kaolin of $15 \mathrm{~g}$ per $100 \mathrm{~g}$ of fibers). The retention value of kaolin in the case of molasses-free kaolin-filled paper composites was $28.9 \%$, however, it increased to $80.21 \%$ in the case of the molasses-incorporated kaolin-filled paper nanocomposites.

These results show clearly that sucrose -present in molasses- acts as a retention aid for inorganic fillers such as kaolin. It is assumed that, during paper sheet formation, sucrose decreases the collapse of the nanoporous structure of the fibers. This collapse -normally- takes place at paper sheet formation, due to drying of the fibers. Thus, during paper sheet formation, the sucrose-incorporated fibers are more swollen and 
thicker, relative to the sucrose-free fibers. This fiber swelling decreases the size of the gaps present between the fibers, during paper sheet formation. Therefore, lesser amount of inorganic filler can escape through these narrowed gaps, during the water drainage, which occurs at paper sheet formation. Eventually, more inorganic filler is enmeshed between these swollen thickened sucrose-incorporated fibers. We called this type of retention "incorporation retention" to differentiate it from the conventional types of retention of inorganic fillers.

Moreover, the gums and starch -present in molasses- exerted an additional retention aiding effect. 


\section{References}

1. Fahmy TYA, Mobarak F, Fahmy Y, Fadl MH, El-Sakhawy M (2006) Nanocomposites from natural cellulose fibers incorporated with sucrose. Wood Sci. Technol. 40:77-86

2. Fahmy TYA, Mobarak F (2008) Vaccination of biological cellulose fibers with glucose: A gateway to novel nanocomposites. International Journal of Biological Macromolecules 42(1): 52

3. Fahmy TYA (2007) Introducing molasses as a new additive in papermaking. TAPPI J. 6(8): 23

4. Fahmy TYA (2007) Molasses as a new Additive in papermaking: for high alphacellulose wood pulp. Professional Papermaking 4(1): 42

5. Stone J E, Scallan A M, (1968) Structural model for the cell wall of water-swollen wood pulp fibers based on their accessibility to macromolecules. Cellulose Chem. Technol. 2(3):343-58

6. Fahmy TYA, Mobarak F (2008) Nanocomposites From Natural Cellulose Fibers Filled With Kaolin In Presence Of Sucrose. Carbohydrate Polymers 72(4): 751

7. Casey JP (1962) "Pulp and Paper", Interscience Publishers Inc., New York

8. Barnes AC (1974) "The Sugar Cane", World Crop Series, Leonard Hill Books, London.

9. Mobarak F, El-Shinnawy NA, Soliman AAA (1998) Effect of some chemical treatments of upgraded Egyptian Kaolin on its retention by bagasse pulp. Journal of Scientific \& Industrial Research 57 (6): 316-323

10. Mobarak F, Augustin H (1976) Cationic starch in papers with high content of bagasse pulp.2. Influence on filler retention and properties of writing and printing papers. Papier 30 (3): 100-102

11. Mobarak F, Fahmy Y, Augustin H, (1976) Cationic starch in papers with high content of bagasse pulp.1. Influence on strength properties of kraft papers. Papier 30 (1): 1619

12. Roberts JC (1996) "Paper Chemistry", an imprint of Chapmann and Hall. 
Table 1

Analysis and physical properties of the wood pulp

\begin{tabular}{|c|c|}
\hline Alphacellulose \% & 95.00 \\
\hline Pentosanes \% & 4.09 \\
\hline Ash Content \% & 0.15 \\
\hline Water Retention Value (WRV) A.D. \% & 88.82 \\
\hline
\end{tabular}




\section{Table 2}

Effect of filling cellulose fibers (pulp fibers) with the conventional additive (inorganic filler kaolin) -in absence of molasses- on the properties of the produced paper composites

\begin{tabular}{|l|c|c|c|c|c|}
\hline $\begin{array}{l}\text { Amounts of the added kaolin } \\
\text { (in grams per } 100 \text { grams of fibers) }\end{array}$ & zero & 5 & 10 & 15 & 20 \\
\hline Breaking length in meters & 2100 & 1925 & 1851 & 1773 & 1612 \\
\cline { 2 - 6 }$\%$ decrease in breaking length & ---- & 8.33 & 11.85 & 15.57 & 23.24 \\
\hline Wet breaking length in meters & 410 & 355 & 325 & 311 & 293 \\
\cline { 2 - 6 } \\
\% decrease in wet breaking length & ---- & 13.42 & 20.73 & 24.15 & 28.54 \\
\hline
\end{tabular}




\section{$\underline{\text { Table } 3}$}

Effect of incorporating the kaolin-filled cellulose fibers with nanoadditive (molasses) on the properties of the produced advanced paper nanocomposites

\begin{tabular}{|l|c|c|c|c|c|}
\hline $\begin{array}{l}\text { Amounts of the added kaolin } \\
\text { (in grams per 100 grams of fibers) }\end{array}$ & zero & 5 & 10 & 15 & 20 \\
\hline Breaking length in meters & 2100 & 2563 & 2550 & 2531 & 2509 \\
\cline { 2 - 6 } \\
$\%$ increase in breaking length & ---- & 22.05 & 21.43 & 20.52 & 19.48 \\
\hline Wet breaking length in meters & 410 & 482 & 478 & 477 & 473 \\
\cline { 2 - 6 }$\%$ increase in wet breaking length & ---- & 17.56 & 16.59 & 16.34 & 15.37 \\
\hline
\end{tabular}




\section{Table 4}

The Role of the Nanoadditive (Molasses) as a Retention Aid for the Inorganic Filler Kaolin

\begin{tabular}{|l|c|c|c|c|}
\hline $\begin{array}{l}\text { Amounts of the added kaolin } \\
\text { (in grams per 100 grams of fibers) }\end{array}$ & 5 & 10 & 15 & 20 \\
\hline $\begin{array}{l}\text { Retention value of kaolin in case of paper } \\
\text { composites produced from kaolin-filled } \\
\text { molasses-free fibers \% }\end{array}$ & 28.11 & 27.66 & 28.90 & 29.72 \\
\hline $\begin{array}{l}\text { Retention value of kaolin in case of paper } \\
\text { nanocomposites produced from } \\
\text { molasses-incorporated kaolin-filled fibers } \\
\%\end{array}$ & 75.93 & 77.00 & 80.21 & 81.47 \\
\hline $\begin{array}{l}\text { Percentage increase in the retention value } \\
\text { of kaolin, due to molasses-incorporation } \\
\text { into the kaolin-filled fibers \% }\end{array}$ & 170.12 & 178.38 & 177.54 & 174.13 \\
\hline
\end{tabular}

